\title{
Los mercados y el Estado en la evolución del "manifiesto" de Prebisch
}

Edgar Dosman*

\section{Introducción}

Cuando Raúl Prebisch murió en 1986 sus ideas estaban pasadas de moda en el Washington de Ronald Reagan y en las capitales latinoamericanas, desechadas por la mayoría de los economistas occidentales como anticuadas - o incluso peligrosamente equivocadas en la nueva cruzada por la globalización. Sólo los círculos de las Naciones Unidas y un pequeño grupo de partidarios insistían en su contribución permanente. Era como si su vida hubiera sido el mero reflejo de la turbulencia de un siglo breve y violento - como lo denominó Hosbawn (1994)—; ahora que había concluido, con la guerra fría relegada a la historia, también lo estaba (al parecer) el legado de Prebisch. $^{1}$

Ha ocurrido exactamente lo contrario. La vida y obra de Prebisch conservan una importancia contemporánea notable. Su estatura como economista y formulador de políticas ha crecido en vez de disminuir;

\footnotetext{
* Investigador Principal, Centre for International and Security Studies, Toronto. E-mail: edosman@YorkU.CA

${ }^{1}$ El autor expresa un especial agradecimiento a doña Adelita Prebisch por haberle permitido consultar el Archivo Prebisch en Santiago de Chile y citar los documentos que lo componen, así como por su irrestricta colaboración personal para investigar la vida y obra de Raúl Prebisch. Desea agradecer también la gentil colaboración de Eliana Prebisch y la Fundación Prebisch en Buenos Aires; a Adolfo Gurrieri y David H. Pollock por sus observaciones sobre el manuscrito; y a la CEPAL en general por su cooperación a través de los años.
}

y el reconocimiento de la magnitud de su aporte sigue expandiéndose a medida que los académicos recopilan fuentes y manuscritos inéditos. Resulta que Prebisch se conserva muy bien. El tema central de sus preocupaciones desde los años veinte hasta el diálogo Norte-Sur era la relación entre los mercados y el Estado; hoy la globalización y los descontentos con ella (o la "globalización civilizadora", como la han denominado algunos autores) sigue siendo el desafío central tanto para América Latina como para la mayor parte de la humanidad. Por este motivo, vale la pena examinar nuevamente la inmensa contribución de Prebisch - tanto los desafíos que encaró como los conceptos e instrumentos de política que desarrolló mediante el ensayo y error para hacer frente a los desafíos que planteaba el desarrollo en Argentina, América Latina y el mundo. ${ }^{2}$

Ninguna persona de su estatura ha sido tan olvidada e incomprendida en la literatura como Raúl Prebisch. Esto no significa sostener que no haya contribuciones importantes de destacados académicos sobre determinadas etapas de su vida. De hecho,

\footnotetext{
2 Para mayores referencias de las pasiones que despertó Prebisch, véase Dosman y Pollock, 1993, pp. 11-43. Un ejemplo decidor del vilipendio constante de Prebisch por inducir a error a los líderes del Tercer Mundo se menciona en Crossette (1999): el ex Primer Ministro de Singapur Lee Kwan Yew sostenía haber leído y escuchado todos los argumentos de autores como el economista argentino Raúl Prebisch, y al parecer habría dicho que eran estupideces, pero que otros líderes las creían porque 'satisfacían la emotividad'.
} 
existe una abundante bibliografía que continúa enriqueciéndose. ${ }^{3}$ Más bien, el obstáculo que ha amagado desde un principio la realización de estudios sobre Prebisch ha sido la incapacidad persistente de integrar las dimensiones académica y normativa de su vida. Hay una dicotomía aparente en la vida y obra de don Raúl, en que el registro histórico predominante proyecta una imagen dual, casi una doble personalidad, entre sus períodos en Argentina y en las Naciones Unidas. Uno es el Raúl Prebisch internacional de la CEPAL, la UNCTAD y más allá — pensador radical y fundador del estructuralismo; innovador y creador de instituciones; luchador incansable por la justicia en las relaciones regionales y mundiales; la pesadilla de Washington durante sus años cepalinos; vibrante, elegante, con carisma y compasión - un líder auténtico y singular desde el momento en que en 1949 presentó su "manifiesto" en el segundo período de sesiones de la CEPAL en La Habana. El "otro" Prebisch, cuando servía al Estado argentino, estaba vinculado con la oligarquía argentina y la restauración conservadora entre 1930 y 1943, conocida también como la "década infame". De hecho, se benefició del golpe militar del 6 de septiembre de 1930 del general Uriburu que inició este período, fue nombrado Subsecretario de Hacienda a los 29 años, con cometidos cada vez más importantes hasta 1943, que culminaron con su creación del Banco Central, que dirigió como gerente general hasta su despido al término de la restauración conservadora. ${ }^{4}$

De hecho, en la vida y obra de Prebisch hay una unidad fundamental - no hay una doble personalidad, dicotomía o imagen dual-y la clave para conocer su legado permanente como pensador radica en vincular sus períodos en Argentina y las Naciones Unidas. Las culpables de limitar por tanto tiempo la investigación bibliográfica sistemática han sido, por una parte, la complejidad de la vida de don Raúl como actor y pensador y, por otra, la excepcional turbulencia que afligió a Argentina y el sistema mundial durante la Segunda Guerra Mundial y después de ella. Ante todo, se ha prestado poca atención a los años transcurridos entre su despido del cargo en octubre de 1943 y su presentación de El desarrollo de la América Latina y algu-

\footnotetext{
${ }^{3}$ Entre los trabajos de los estudiosos de Prebisch figuran las contribuciones excepcionales de Joseph L. Love, Carlos Mallorquín, Ronald Sprout, Octavio Rodríguez, Kathryn Sikkink, Cristobal Kay, Adolfo Gurrieri, Leopoldo Solís, Manuel Fernando López y muchos otros. Para estudios recientes, véase Ocampo (2001) y Rodrik (1997 y 2000).

${ }^{4}$ Dosman y Pollock, 1993, pp. 16-26. Estudios más recientes son los de Dosman y Pollock (2001) y Lorenzutti (1996).
}

nos de sus principales problemas en el segundo período de sesiones de la CEPAL en La Habana en junio de 1949 (Prebisch, 1949). El Archivo Prebisch, ahora disponible en Santiago, contiene nuevo material en abundancia, que comprende muchos manuscritos y correspondencia que abarcan desde sus años jóvenes hasta sus años cepalinos, y documentan la evolución de su pensamiento sobre los mercados y el Estado desde su salida del Banco Central en 1943 hasta su "manifiesto" de La Habana en 1949. El presente artículo representa el primer paso en esta tarea más amplia de profundizar la literatura académica sobre los orígenes de la tesis cepalina. ${ }^{5}$

\section{El desarrollo "hacia adentro" (1943)}

No cabe duda de que el 18 de octubre de 1943, el día en que fue despedido del Banco Central, fue la experiencia más dolorosa de su vida. El Banco Central había sido un logro notable, la adaptación de un modelo de Niemeyer de manera tal que podía desempeñar el papel de un organismo central en la política monetaria y financiera, con responsabilidades y facultades crecientes después de 1935, pero conservando su autonomía frente a la arena política como una empresa mixta del sector público-privado. La manera en que se le echó — remunerado sólo al día, rechazado para ocupar otro empleo, con la universidad en huelga y sumida en el caos, y con un lastre: un hombre honrado en un Estado corrupto- se sumó a la sensación de ruptura. De ser el ejecutivo más atareado de Argentina, había pasado a ser un intelectual aislado, condenado a mantenerse al margen en Mar del Plata para observar la transformación del sistema internacional en la posguerra bajo la égida de los Estados Unidos, así como el cierre político y económico de Argentina bajo el peronismo. Prebisch decidió emplear su tiempo en escribir un libro sobre sus experiencias como gerente general del Banco Central, y abordar también los desafíos de posguerra que encaraba Argentina con las recomendaciones necesarias para preparar al país para una transición exitosa. Si ya no era bienvenido en el seno del gobierno, y nadie más quería darle empleo, podía al menos divulgar sus planteamientos en una obra. Durante quince años, desde 1928 en el Banco de la Nación Argentina y luego en el Ministerio de Hacienda y el Banco Central, había acumulado un impor-

\footnotetext{
${ }^{5}$ En Toye y Toye (por publicarse) se hace una contribución lúcida y valiosa a este tema.
} 
tante acervo de ideas en torno a la tarea de dirigir la principal economía emergente del mundo; su renuncia forzosa le permitió - por pequeña que fuese esta compensación- el lujo de tiempo libre para reflexionar. Había conducido grandes instituciones sin disponer del tiempo necesario para la investigación académica; especialmente desde el estallido de la guerra en 1939 su labor había sido de tal intensidad que apenas paraba en la facultad incluso para dirigir seminarios. Había dirigido publicaciones oficiales como los Informes anuales del Banco Central o escrito artículos para $L a$ Nación, donde se le identificaba como "un alto funcionario de gobierno", pero había sido un práctico y no un académico; un tecnócrata del sistema gobernante. ${ }^{6}$ Raúl podía dedicarse ahora a pensar sirviéndose de las lecciones de su experiencia desde su llegada a Buenos Aires como estudiante en 1918; en esencia, significaba integrar sus experiencias personales entre 1928 y 1943 con sus escritos y material de conferencias en la facultad. Raúl sabía que podía ofrecer un estudio sin par de la respuesta de Argentina a la gran depresión y de los éxitos y fracasos de las políticas elaboradas mediante ensayo y error durante los años treinta. No existía ninguna publicación detallada sobre los orígenes y el funcionamiento del Banco Central de la República Argentina, y sabía que podía ofrecer una descripción sin paralelo del papel que éste había desempeñado como organismo central desde su creación en 1935.

Sin embargo, era evidente que el libro que se proponía escribir, titulado "La moneda y el ritmo de la actividad económica", tenía que ir más allá de su experiencia en el Banco Central para abordar tanto la teoría como la práctica. Ya el 13 de diciembre, fecha en que había completado su borrador, Raúl había decidido que era necesario innovar. "El contacto estrecho que he tenido con la realidad monetaria del país en los últimos quince años", señalaba Raúl, "me ha persuadido de la necesidad de recurrir constantemente al razonamiento teórico para comprender y resolver mejor los problemas concretos", y que se requería "una explicación teórica distinta" para conocer y explicar la posición de Argentina en el sistema económico internacional. La política monetaria y financiera era de fundamental importancia para Argentina; el Banco

\footnotetext{
${ }^{6}$ El Archivo Prebisch representa una fuente indispensable para estos trabajos, gran parte de los cuales no están incluidos en la publicación en cuatro volúmenes Raúl Prebisch: Obras 1919-1949 (Prebisch, 1991a).
}

Central había sido creado porque las alternativas habían fracasado. Había iniciado "un período de experiencias y tanteos, desaciertos y errores" de los cuales podían y debían "desprenderse enseñanzas para elaborar la política futura”. Pero para que el libro fuera creíble no sólo tenía que remontarse a la experiencia previa, sino también mirar al futuro. Los desafíos encarados por Argentina durante la gran depresión y la guerra irían seguidos de nuevos problemas al sobrevenir la paz; y las soluciones serían igualmente difíciles de alcanzar. La teoría económica liberal tradicional ofrecía a los gobiernos argentinos un marco de análisis inadecuado del cual extraer las prescripciones de política pertinentes y por tanto se requería un enfoque alternativo para interpretar el lugar y el papel de Argentina en el sistema económico internacional. ${ }^{7}$

Pregunta 1: ¿Cuáles eran los objetivos nacionales de la política monetaria y financiera? Visualizaba tres: evitar el ciclo de auge y depresión mediante el control de los violentos altibajos de los precios agrícolas y otros impactos del comercio exterior sobre la economía; el fortalecimiento del desarrollo y la mantención del pleno empleo; y la estimulación de la tasa de crecimiento económico más acelerada posible. No había vuelta atrás. La industrialización había desencadenado la creatividad nacional y el crecimiento debía seguir aprovechando ese "enorme potencial".

Pregunta 2: ¿Cuál debería ser el papel del comercio internacional? Raúl subrayaba la necesidad de establecer un sistema comercial abierto. Era esencial evitar lo que ocurrió después de la Primera Guerra Mundial, señalaba, cuando "las exportaciones del resto del mundo a Estados Unidos" se bloquearon, lo que condujo a un círculo vicioso de restricciones comerciales y controles, y la división de la economía mundial en "compartimientos estancos" durante los años treinta. Por tanto, la globalización con un sistema crediticio y de comercio multilateral bien afianzado era una condición previa para que Argentina prosperara después de la guerra - pero no era suficiente-. Harry Dexter White y John M. Keynes estaban preparando una conferencia para julio de 1944 destinada a idear un plan de posguerra para reactivar el comercio y estabilizar la economía internacional. Concluía Prebisch que la labor de White y Keynes era vital para todos los países

\footnotetext{
${ }^{7}$ Raúl Prebisch, "La moneda y el ritmo de la actividad económica", manuscrito inédito de diciembre de 1943 encontrado en el Archivo Prebisch. Citas ulteriores en la presente sección provienen de este importante documento (Prebisch, 1943).
} 
comprendida Argentina, pero que las políticas de este país tenían que reflejar sus propias necesidades dentro de este sistema en evolución.

Pregunta 3: ¿Por qué debe Argentina procurar la industrialización? Porque ni la doctrina de la ventaja comparativa, ni el funcionamiento del ciclo económico operan automáticamente para las economías emergentes como Argentina. Raúl concluía de su experiencia que la relación de intercambio para los productores agrícolas básicos como Argentina estaba en una declinación histórica. La denominó "una baja persistente de los precios internacionales de nuestras exportaciones". Pero la relación de intercambio declinante sólo acentuaba un desequilibrio estructural más profundo, o equilibrio intrínseco, del sistema internacional. Según los economistas liberales occidentales, el mecanismo de mercado beneficiaba automáticamente a todos los países, las grandes economías industrializadas y las agrícolas, y el ciclo económico regulaba los altibajos de la economía internacional. Raúl discrepaba; sostenía en cambio que el sistema económico internacional funcionaba con un desequilibrio permanente porque el ciclo económico opera con reglas diferentes para los países industriales y agrícolas como Argentina, que "presenten en nuestra vida económica ciertas características comunes que se prestan a esbozar una explicación teórica distinta". Prebisch ya había concluido en sus Anotaciones sobre nuestro medio circulante de 1921 (donde empleó por primera vez los términos "centro" y "periferia", una metáfora elaborada localmente durante el debate nacional sobre la concentración de la riqueza y el poder en la metrópolis costera de Buenos Aires, que extraía la riqueza de las pampas subpobladas) que el ciclo económico de Argentina creaba un fenómeno atípico de auge y depresión porque carecía de los mecanismos de autocorrección característicos de las economías industriales (Prebisch, 1991b). Desde entonces había vivido el desplome bursátil pos 1918, el auge de los años veinte, la gran depresión, la recuperación pos 1934, y ahora la Segunda Guerra Mundial.

Ningún país había aspirado más que Argentina a la ortodoxia comercial y monetaria en la búsqueda ilusoria de una vuelta a la "normalidad". Había suspendido el patrón oro por treinta días el 20 de agosto de 1914, creyendo que el retorno a la convertibilidad era inminente; luego una y otra vez por intervalos de treinta días hasta diciembre de 1927, cuando finalmente se restableció el patrón oro. Después de dos años desastrosos volvió a suspenderse, y permanecía así en 1943.
En 29 años el sistema no había funcionado "normalmente" en absoluto. En más de tres cuartos de siglo la convertibilidad sólo había durado 23 años.

Pregunta 4: ¿Por qué promover el desarrollo? En la práctica Argentina había sido obligada a abandonar el libre comercio y elaborar los instrumentos para convertirse en un Estado activo orientado por el Banco Central. Ahora que la guerra estaba llegando a su fin, el Estado argentino tendría que conservar este papel porque el desarrollo nacional no ocurriría automáticamente. Según Prebisch, sólo un Estado activo podía escudarlo de una vulnerabilidad permanente en relación con los Estados industriales, con la función primordial de basarse en el tipo de intervenciones calculadas creadas por el Banco Central desde 1935 para manejar la turbulencia, y asegurar con ello que Argentina seguiría siendo un socio de pleno derecho y no un país marginal dependiente en la emergente economía global. Se había iniciado un nuevo período porque Argentina tenía que arreglárselas para salir de este problema o encarar la marginalización. "Pero para que ello no signifique una constante subordinación de la economía nacional a los movimientos y contingencias de afuera, necesitamos desarrollarnos hacia adentro, fortalecer nuestra estructura interna y conseguir el funcionamiento autónomo de nuestra economía”. Los conceptos iniciales de Prebisch sobre el libre comercio están bien documentados. Todavía en 1927 en una polémica con el profesor visitante español Luis Olariaga, rechazaba el proteccionismo con el argumento de que Argentina se había beneficiado tanto como los Estados Unidos, Canadá o Australia al especializarse en el comercio de productos básicos (Prebisch, 1991c). Tampoco es necesario repetir los detalles de este cambio gradual hacia el intervencionismo mientras era Subsecretario de Hacienda y con el Plan de recuperación nacional, de fines de $1933 .{ }^{8}$ Sencillamente la experiencia vivida modificó el enfoque de Prebisch frente a los mercados. En la práctica, Argentina había sido obligada a abandonar el libre comercio y desarrollar un Estado más activo en el primer Plan de Recuperación Nacional; la creación del Banco Central en 1935 había reducido de hecho la vulnerabilidad de Argentina durante la depresión y la guerra, domando el ciclo económico. Las grandes obras públicas habían generado empleo. Raúl era un economista intuitivo y no un académico típico que buscaba el debate erudito mediante las revistas especializadas. Ante la disyuntiva entre compro-

\footnotetext{
${ }^{8}$ La obra definitiva al respecto es Love, 1994, pp. 393-601.
} 
miso y reflexión, había elegido el servicio público en los años veinte, a pesar de su compromiso con la economía y una codiciada cátedra en la Facultad de Ciencias Económicas desde 1925. Siendo fundamentalmente un hombre de acción, su construcción de teorías emanaba tanto de la experiencia como de la investigación académica.

Pregunta 5: ¿Cuál debería ser el papel del Estado en promover la industrialización? Prebisch preconizaba un "régimen inteligente", o un Estado sagaz. Si bien el Estado debía apoyar la industrialización, la economía en su conjunto debía seguir impulsada por el sector privado para que prosperara. Por tanto, la intervención estatal era tan perjudicial como la aceptación ingenua de la doctrina de la ventaja comparativa. No hay que sofocar al sector privado, advertía Prebisch. Un sector privado y un clima de inversión saludables eran esenciales para el éxito económico y una estrategia de inversión acertada. Argentina necesitaba un Estado activo, pero dentro de una asociación juiciosa entre el sector público y el privado. "De muy poco o nada servirá el estímulo monetario si se sofoca la iniciativa privada y el espíritu de empresa que requieren ineludiblemente el incentivo de la ganancia y un ambiente general de confianza".

Un ejemplo de una iniciativa de apoyo a la industria en 1941 era la Corporación de Fomento a las Exportaciones - llamada también Instituto Argentino de Promoción del Intercambio (IAPI), pero muy diferente a la creación de Perón en 1946- con oficinas en los Estados Unidos, para desarrollar productos de exportación nuevos y no tradicionales destinados a reemplazar los productos europeos bloqueados por la ocupación alemana. Administrada por una junta del sector privado, rendía cuentas en última instancia al Banco Central. ${ }^{9}$ Pero el corolario de la apertura al sector privado era la responsabilidad de este último de mantenerse competitivo. En el último informe anual del Banco Central preparado bajo la dirección de Prebisch, que se ocupaba de los preparativos para el período de la posguerra, es evidente que su apoyo a la industria-

\footnotetext{
9 Estados Unidos, Departamento de Estado, Memorandum de la Embajada de los Estados Unidos en Argentina a Washington, del 29 de noviembre de 1940, que delinea los objetivos y la estructura del nuevo IAPI, así como las conversaciones de Prebisch con funcionarios de la Embajada y del Departamento de Estado. El Subsecretario de Estado Sumner Wells señalaba el 7 de enero de 1941 (durante la prolongada visita de Prebisch a la capital estadounidense) que el proyecto entrañaba cuestiones prácticas y de política de cierta importancia.
}

lización no implicaba la protección sistemática de las empresas ineficientes y no competitivas que habían surgido desde la depresión. ${ }^{10}$

Pregunta 6: ¿Qué pasa con la política de posguerra? A juicio de Prebisch, el imperativo de la política de posguerra de comercio e industrialización requería la combinación juiciosa de la sustitución de importaciones y la promoción de exportaciones en vez de un proteccionismo indiscriminado. "La autarquía es tan absurda como el libre cambio", concluía Prebisch, "con consecuencias perniciosas... Esta posibilidad de realizar importaciones crecientes bajo un régimen de inteligente selección y una adecuada política de prudente estímulo de orden monetario, cada vez que sea indispensable, pueden favorecer intensamente el desarrollo de la industria y dar a ésta, y por natural repercusión a los otros sectores de la economía, una fuerza de atracción inmigratoria similar a la que tuvo largamente la tierra en épocas anteriores de fuerte crecimiento económico y demográfico". Según Prebisch, tener un sector privado competitivo después de la guerra implicaba sanear la economía, aprovechando los sectores industriales viables creados durante el conficto bélico y eliminando las industrias ineficientes y no competitivas que habían surgido bajo el proteccionismo forzoso de la guerra mundial. La misma precaución se aplicaba al gasto del Estado, que debía mantenerse prudente y no inflacionario. "Hay que llegar a un equilibrio razonable entre la acción del Estado y el juego de los intereses individuales en la vida económica". Además, Prebisch advertía contra la política de los extremos. Había que asegurar un equilibrio entre la productividad y la política social para mantener el crecimiento, en vez de recurrir a un gasto público excesivo. La inflación era un peligro constante. La economía argentina ya estaba con pleno empleo y en peligro de recalentamiento, y el gobierno debía resistir por tanto las presiones políticas para que incurriera en un gasto inflacionario. Aunque Argentina tenía que mejorar las condiciones de los pobres, Prebisch apelaba a una política social coordinada con la productividad económica nacional para impedir los déficit y la inflación. "Téngase siempre presente que el común denominador de los problemas sociales es el aumento de la producción. Sin ello, no habrá elevación estable del nivel de vida de las masas". Argentina sólo podía mantener su buen

\footnotetext{
${ }^{10}$ Esto se advierte también claramente en el texto que Prebisch escribió para el discurso del general Agustín P. Justo ante la Cámara de Comercio Británica el 22 de noviembre de 1942 (Archivo Prebisch).
} 
prestigio si el Gobierno adoptaba la combinación de políticas correcta; la política interna tenía que fomentar el crecimiento sostenido porque Argentina dependía tanto del Estado como de la actividad industrial central para que las economías configuraran las condiciones para la prosperidad. Pese a las múltiples incertidumbres, Prebisch pronosticaba un futuro positivo para Argentina. Naturalmente que su prosperidad no estaba garantizada automáticamente por su éxito relativo durante la última década, pero el país tenía los instrumentos de política necesarios para alcanzar la estabilidad y el crecimiento. El éxito de Argentina en salir adelante de la gran depresión y la experiencia de la guerra le habían brindado una confianza renovada y prestigio internacional; había hecho grandes avances desde 1930 y podía aguardar la era de posguerra con confianza y no con temor, como un actor joven y vigoroso del Nuevo Mundo en el escenario internacional.

Pregunta 7: ¿Qué es lo que define el desafío teórico de Prebisch? El enfoque de Prebisch prometía una mezcla singular y profética de radicalismo teórico y activismo estatal keynesiano, pero dentro de la preocupación que tiene un banquero por el dinero seguro y por el sector privado. En el plano teórico, retaba en suelo sagrado a los economistas liberales tradicionales de occidente al contradecir los supuestos de equilibrio y ventaja comparativa en la economía internacional, puesto que estos últimos no habían superado la prueba empírica que él había propuesto de elaborar un enfoque teórico más acorde con la intuición, la observación y la experiencia de Argentina. Pero Prebisch no era en modo alguno un crítico revolucionario del capitalismo occidental. Rechazaba el comunismo, y confiaba en que Argentina podría desarrollar los instrumentos necesarios para encarar el desafío de posguerra. El libro bosquejado por Prebisch promovía, en cambio, un enfoque que podría denominarse "globalización civilizadora"; estimaba que Argentina no tenía otra opción que abrazar la globalización, fortalecer los lazos comerciales con sus vecinos, reconocer la declinación de Gran Bretaña y aceptar que el liderazgo de los Estados Unidos era inevitable en el sistema internacional emergente. Pero insistía en que el Estado argentino, el sector privado y la sociedad podían y tenían que asumir la responsabilidad de las opciones de política para garantizar el desarrollo sostenible.

\section{Hacia el "manifiesto"}

Sólo cabe especular sobre el impacto de esta obra si se hubiera escrito y publicado. El bosquejo seductor de Prebisch de diciembre de 1943 sobre la declinación de la relación de intercambio mundial; su hipótesis del desequilibrio estructural en el sistema económico internacional y la proyección de un nuevo marco teórico para el desarrollo; su llamamiento a la industrialización y a una combinación de exportaciones que trascendiera a los productos básicos; y su noción de Estado sagaz con coherencia administrativa para combinar los mercados abiertos con intervenciones calculadas y procesos deliberados, eran extraordinariamente promisorios desde el punto de vista académico. Ya en 1943 Prebisch había propuesto el salto conceptual que desafiaría a los economistas occidentales en su propio terreno. El manuscrito es un punto de referencia esencial de su pensamiento en ese año, al término de su carrera en el Banco Central, y demuestra que había elaborado su concepto del "desarrollo hacia adentro" mucho antes de la creación de la CEPAL, y que esa elaboración teórica estaba más adelantada de lo previsto.

Pero su propuesta fue rechazada por los editores argentinos, y por tanto no tenía otra opción que continuar el proyecto mientras enseñaba en la facultad y se ganaba la vida. Esperaba sacarlo pronto - algunos amigos como Robert Triffin ya lo solicitaban en 1945 - , pero en realidad, en 1943, todavía faltaba para que el "manifiesto" de La Habana hiciera su aparición. La vida en Buenos Aires lo deprimía cuando el peronismo asumió el poder en 1946 y observaba el creciente aislamiento y declinación cultural de Argentina. Asimismo, tenía que realizar consultorías para sobrevivir y esto entorpecía también su labor, aunque el descubrimiento de la riqueza, belleza y potencial de América Latina más allá del Cono Sur en sus visitas a México, Colombia y Perú en 1944, y sus viajes ulteriores a Paraguay, Venezuela, Guatemala y otros países, fueron fundamentales para la evolución de su visión regional. La falta de recursos para la investigación, y sobre todo el problema de trabajar aislado, sin colaboradores, también retardaba su labor. En muchas ocasiones envidiaba a los académicos de las universidades norteamericanas y europeas que podían dedicarse plenamente a su labor académica. ${ }^{11}$

Después de 1946, a Prebisch le fue cada vez más difícil continuar enseñando en la facultad, y finalmente fue obligado a dejar la universidad el 15 de noviembre de 1948 con su proyecto de libro todavía incon-

\footnotetext{
${ }^{11}$ Por ejemplo, en carta a Eugenio Castillo del 23 de noviembre de 1948 (Archivo Prebisch, Correspondencia) describe su situación en Argentina como "la ingrata posición del investigador solitario".
} 
cluso. ${ }^{12}$ Con posterioridad a 1943 había viajado y trabajado mucho por toda América Latina, pero siempre había resistido las oportunidades de trasladarse a los Estados Unidos o México. Ahora tenía que reconsiderar su posición, y las opciones se reducían a un alto cargo en el Fondo Monetario Internacional (FMI) o a una consultoría de corto plazo en la CEPAL en Santiago. De las dos, Prebisch prefería infinitamente esta última. Camille Gutt, el Director Gerente del FMI, acompañado del Subdirector, Edward M. Bernstein, había visitado Buenos Aires el 25 de noviembre, diez días después de la salida de Prebisch de la universidad, y había formulado un ofrecimiento que Raúl aceptó. No se había suscrito un contrato propiamente tal en espera de la aprobación del Directorio Ejecutivo del Fondo, pero el señor Gutt había desechado esto como una formalidad. Sin embargo, el silencio perturbador de Washington tras esta visita sugería problemas, y el rechazo humillante y doloroso de Prebisch por parte del FMI brindó el telón de fondo personal que fue esencial para el surgimiento del "manifiesto" de La Habana.

La primera señal de oposición interna apareció pronto, el 23 de diciembre, cuando Gutt cablegrafió anunciando que el contrato de empleo tendría que modificarse. "He examinado nuestras últimas conversaciones con los jefes de departamento. Consideran que un asesor externo a las líneas departamentales no es factible. Dispuesto a recomendar su nombramiento en el Departamento de Operaciones con el sueldo propuesto". ${ }^{13}$ Pero a Prebisch se le dieron seguridades de que el cambio era simplemente para no sentar un precedente en el Fondo y que el ofrecimiento se confirmaría pronto. M. H. Parsons, del Departamento de Operaciones, le comunicó que la demora en la aprobación era meramente técnica - la epidemia de influenza de enero había raleado el Directorio Ejecutivo-; esperaba que éste se reuniera antes de fines de enero. "Esperamos contar con usted y aprovechar su gran experiencia, sobre todo en nuestras relaciones con América Latina". ${ }^{14}$

\footnotetext{
${ }^{12}$ Prebisch terminó por declinar un ofrecimiento en 1945, gestionado por Robert Triffin, para visitar Harvard y enseñar en los Estados Unidos; participaron tanto la Fundación Guggenheim como la Rockefeller, y el Secretario de Estado adjunto Nelson Rockefeller señaló que estaba "muy interesado en el viaje que se ha propuesto a Raúl para ir a Harvard y estoy encantado de saber que los planes están progresando y tan pronto como él adopte una decisión definitiva, le agradecería que me comunicara la fecha de su venida" (Memorandum del Departamento de Estado de los Estados Unidos, 9 de febrero de 1945). Prebisch también rechazó un ofrecimiento para ocupar un alto cargo en el Banco de México después de la elección de Perón en 1946.

${ }^{13}$ Archivo Prebisch, Correspondencia: June Eckard a Raúl Prebisch, 22 de marzo de 1949.

14 Archivo Prebisch, Correspondencia: M.H. Parsons a Raúl Prebisch, 19 de enero de 1949.
}

Así, muy tranquilizados, Raúl y Adelita Prebisch continuaron los preparativos de su partida, mientras Urquidi y otros amigos rastreaban el mercado de bienes raíces en la capital estadounidense y su periferia. Se celebraron despedidas, y Raúl preparaba las conferencias que dictaría en México a contar del 16 de febrero. En la víspera de su partida Raúl recibió más buenas noticias del FMI; Parsons sugería que se reunieran en México durante su seminario en la Universidad Nacional Autónoma de México (UNAM) para analizar un plan de trabajo. La aprobación del Directorio Ejecutivo era ahora inminente, manifestaba. Era un mes ajetreado que auguraba un buen futuro, pese al impacto emocional de dejar Buenos Aires. ${ }^{15}$ Sin embargo, Adelita guardaba cama en Mar del Plata y no pudo acompañarlo a México cuando partió el 15 de febrero; al llegar al Hotel Reforma le cablegrafió su afecto.

Pero cuando Prebisch inauguró su seminario el 16 de febrero, era claro que la retención de su nombramiento tan discutido en el FMI tenía poco que ver con la enfermedad del Directorio Ejecutivo. Parsons no llegó; no supo nada de Washington. Para mortificación de Raúl, los rumores de la oposición del Tesoro estadounidense a su nombramiento se convirtieron en chismes de pasillo en México. Concluido el seminario, Prebisch decidió presionar al FMI y cablegrafió a Gutt el 6 de marzo exigiendo una respuesta definitiva. El Director Gerente primero le dio largas al asunto con un mensaje que pedía más tiempo, pero luego confirmó que el Directorio Ejecutivo había rechazado en efecto su nombramiento. Parsons le envió una carta personal de disculpa el 11 de marzo. "Nos hemos comportado de manera intolerable... no sé qué es peor, sentirme avergonzado de mí mismo, o sentirme avergonzado de la organización en que trabajo. Nos costará caro esta insensatez de prescindir de sus servicios y del prestigio que podría haber brindado al Fondo en sus relaciones con América Latina. No le pido que sea tolerante con nosotros porque pienso que nos hemos conducido de manera intolerable, pero sí le pido que nos compadezca por tener que añadir una insensatez de esta especie a una carga que ya es demasiado pesada. Los dioses enloquecen primero a quienes desean destruir". ${ }^{16}$ Concluía la misiva "Con profundo pesar". Raúl compartió su decepción por teléfono con Adelita, que ahora se estaba recuperando. Ella se mostró feliz de no tener que

\footnotetext{
${ }^{15}$ Archivo Prebisch, Correspondencia: M.H. Parsons a Raúl Prebisch, 10 de febrero de 1949.

16 Archivo Prebisch, Correspondencia: M.H. Parsons a Raúl Prebisch, 11 de marzo de 1949.
} 
ir a Washington y tratar con gente tan indecorosa, y predijo que algún día se cambiarían los papeles. ${ }^{17}$ Robert Triffin y otros amigos contaron la verdadera historia de por qué el FMI lo había rechazado. ${ }^{18} \mathrm{El}$ asunto se había transformado en una cause célèbre interna porque los Estados Unidos habían revertido su posición y ahora se oponían a su candidatura, aunque en un principio el Tesoro la había apoyado. Esto resultaba embarazoso y desagradable; el Fondo lo había ido a buscar a Buenos Aires, y no a la inversa, y un compromiso tan firme no se habría suscrito jamás si los Estados Unidos no hubieran estado de acuerdo. Es más, Prebisch era el banquero central y economista más conocido de América Latina; no había manera de explicar el súbito rechazo cuestionando su competencia. Por tanto, la lucha por Prebisch en el Fondo fue larga y enconada.

Una serie de factores complejos se hallaba tras la negativa de Washington a aceptar su nombramiento a principios de 1949, y no tenían nada que ver con el rumor de que los veteranos de Washington recordaban la dureza de Prebisch durante las negociaciones bilaterales de los años treinta con los Estados Unidos y ahora le devolvían la mano por haber favorecido a Gran Bretaña después del tratado Roca-Runciman. En cambio, la decisión estadounidense reflejaba la nueva apertura de las relaciones diplomáticas entre Estados Unidos y Argentina; la oposición brasileña al nombramiento, y el clima político cambiante en Washington. Perón se oponía enérgicamente a que Prebisch ocupara algún cargo influyente en el FMI aunque Argentina no era miembro del Fondo; si bien había aceptado seis meses antes apoyar su candidatura a la CEPAL (presumiblemente para sacarlo cómodamente de Buenos Aires a ocupar una posición marginal en Santiago), el presidente argentino no quería tener un connacional opositor en un cargo clave en Washington. No obstante, considerando el congelamiento profundo de las relaciones entre ambos países desde Pearl Harbour, esa oposición previsible no debería haber preocupado a Washington, todo lo contrario. La embajada estadounidense había hecho campaña abiertamente contra Perón en 1946, quien más tarde había denunciado el Plan Marshall como un flagelo y un desastre para Argentina. ${ }^{19}$ Sin embargo, el 19 de enero de 1949 Perón des-

\footnotetext{
17 Archivo Prebisch, Correspondencia: Adela Prebisch a Raúl Prebisch, 13 y 30 de marzo de 1949.

${ }^{18}$ Archivo Prebisch, Correspondencia: June Eckard a Raúl Prebisch, 22 de marzo de 1949.

${ }^{19}$ Lewis, 1990, pp. 191-192.
}

pidió al equipo económico encabezado por Miguel Miranda y Washington vio una oportunidad de mejorar las relaciones bilaterales. Se estableció un comité conjunto bilateral para examinar las cuestiones económicas, incluida la apertura potencial de la inversión petrolera estadounidense; Washington procuraba restablecer su posición de preguerra en Argentina, entonces el mercado más importante de América Latina, con activos mayores que todos los demás países en 1943, excepto Cuba y Canadá, y que ahora estaba amenazado por la expansión europea del comercio bilateral y la escasez de dólares. ${ }^{20}$ Por ende, el nombramiento de Prebisch quedó atrapado en una reorientación diplomática bilateral, en que el Departamento de Estado sostenía que el apoyo estadounidense a Prebisch en el FMI podía anular este avance promisorio con Perón. Echado del Banco Central en 1943 —pese a las protestas estadounidenses - por el gobierno militar respaldado por Perón, este hombre que había arriesgado y perdido su carrera por la causa aliada y que había continuado trabajando en estrecha colaboración con la Reserva Federal después de 1945, era sacrificado seis años más tarde en aras del acercamiento Estados Unidos-Perón.

Había en juego otro factor menos tangible en el rechazo de Prebisch por los Estados Unidos. Raúl no sólo carecía del respaldo de su país, sino que también era vulnerable en el ambiente político cambiante de Washington, ahora irreconocible respecto de las circunstancias que rodearon su salida del Banco Central en 1943. Había colaborado con la Reserva Federal de los Estados Unidos en toda América Latina, y todavía conocía a algunos de sus funcionarios, como David Grove, jefe de la sección latinoamericana en el departamento de investigaciones. En aquellos años, podía también haber escogido su empleo entre los bancos estadounidenses: el Chase Manhattan Bank se refería a él casi como a un miembro de la familia; Joseph C. Ravensky señalaba en su carta de retiro enviada a Raúl en 1945 "usted es tan de la casa que no me va a echar mucho de menos". ${ }^{21}$ Pero los tiempos habían cambiado. Prebisch ya no era muy conocido en Washington, y los amigos que todavía lo tenían en gran estima, como Triffin y Wallich, sintonizaban cada vez menos con la creciente ideología de la guerra fría en los círculos oficiales. Ellos representaban la generosidad

\footnotetext{
20 Estados Unidos, Departamento de Estado (1949), Internal Memorandum 835.5151/7-149. Véanse más antecedentes en Escudé, 1981.

${ }^{21}$ Archivo Prebisch, Correspondencia: Joseph C. Ravensky a Raúl Prebisch, 28 de diciembre de 1945.
} 
e innovación de la política estadounidense hacia América Latina durante la guerra. Un enfoque renovado y más duro hizo de Prebisch un afuerino en el Washington de Truman. La apertura estadounidense hacia América Latina concluyó después de 1945 y dio paso a una era diferente en Washington. Las múltiples invitaciones de destacadas universidades estadounidenses se terminaron abruptamente; Triffin, Williams y Hansen dieron paso a Gottfried Haberler, Jacob Viner y una visión más estrecha de los mercados. Una oleada de anticomunismo, todavía sin caracteres de histeria, en la capital estadounidense exigía el máximo cuidado para elegir personas destacadas para el FMI y el Banco Mundial; si bien nadie podía sostener que Prebisch era filocomunista, sí era un latinoamericano que empleaba términos como "centro" y "periferia". Con el renacimiento de la economía ortodoxa, organizada principalmente en torno al concepto de equilibrio, que rechazaba la necesidad de corregir el mecanismo de mercado, Prebisch desentonaba terriblemente: al reconocer los desequilibrios intrínsecos del sistema y proponer un papel activo del Estado en la economía, desafiaba el paradigma dominante de posguerra. Prebisch, en suma, no era automáticamente "fiable". Esta nueva cautela que infiltraba el proceso de selección del FMI era transmitida directamente por el Tesoro estadounidense, pero también internamente por los funcionarios estadounidenses abanderados. E. M. Bernstein, por ejemplo, que había hecho el contacto con Prebisch en Buenos Aires y cuyo apoyo podría haber influido en la aprobación de Raúl, permaneció callado durante el caso. Incluso Ravndahl, que podría también haber influido en el Departamento de Estado, prefirió hacerse a un lado. En último término, el FMI era una organización intergubernamental dirigida por las grandes potencias, y su política no podía escapar al alineamiento ideológico cambiante de la comunidad washingtoniana encargada de la política exterior. Raúl había sido utilizado por Washington para su provecho cuando era poderoso; ahora que era débil podía ser descartado y convertido en el hazmerreír de un extremo al otro de las Américas sin temor a represalias. Los latinoamericanoss recién contratados en el Fondo no podían hacer otra cosa que mirar el espectáculo con frustración y enojo.

Por último, la oposición brasileña a Prebisch fortalecía la determinación de Washington de imponer su veto al nombramiento, y el peso diplomático de Brasil en Sudamérica hacía también que este factor tuviera una considerable importancia en la región. En este caso, sin embargo, no se trataba tanto de política como de envidia. Aunque Octavio Bulhões había enviado a Raúl el 5 de febrero una carta de felicitaciones desde el Ministerio de Hacienda en Río de Janeiro, también convenció al gabinete de vetar el nombramiento en el Directorio Ejecutivo del Fondo. ${ }^{22}$ Eugenio Gudin, que respetaba y apoyaba genuinamente el nombramiento, se hallaba fuera de Río pues estaba siendo sometido a una intervención quirúrgica en los Estados Unidos y por tanto no estaba en situación de impedir la traición. Confrontados por los Estados Unidos y Brasil, otros miembros del Directorio Ejecutivo del FMI terminaron por alinearse.

El rechazo del FMI, sumado al término de su carrera universitaria en Buenos Aires, significaba que a Prebisch le quedaba una última oportunidad. Es decir, la CEPAL. Había sido contactado a fines de 1948 por las Naciones Unidas para ocupar el cargo de Secretario Ejecutivo, pero había rechazado el ofrecimiento, y Gustavo Martínez Cabañas había sido seleccionado en definitiva para comenzar sus labores el $1^{\circ}$ de enero de 1949. No obstante, la CEPAL insistió, ofreciendo a Raúl una consultoría para contribuir a que la nueva organización se preparara para el segundo período de sesiones en La Habana previsto para iniciarse el 26 de mayo. El problema que encaraban Martínez Cabañas y su adjunto, Eugenio Castillo, era cumplir con la tarea principal de la CEPAL tras su primer período de sesiones en junio de 1948 - a saber, producir el primer Estudio Económico de América Latina-, una ingente tarea que jamás se había intentado, y hacerlo en menos de un año, con un equipo totalmente nuevo en Santiago que carecía de profundidad y experiencia. Le suplicaron ayuda a Prebisch, incluso que obtuviera una licencia prolongada del FMI (previendo que estaría en Washington); pero Prebisch no respondió hasta que la debacle del FMI fue evidente, aceptando finalmente una consultoría de corto plazo que incluía la conferencia de La Habana. ${ }^{23}$

En Nueva York, David Owen y altos funcionarios del Departamento de Asuntos Económicos y Sociales de las Naciones Unidas estaban también cada vez más inquietos por el futuro de la CEPAL, y sabían que

\footnotetext{
22 Archivo Prebisch, Correspondencia: Octavio Bulhões a Raúl Prebisch, 11 de febrero de 1949.

23 Naciones Unidas, Correspondencia: Eugenio Gudin a Harold Caustin, Nueva York, 13 de julio de 1948, que trata de los esfuerzos para atraer a Prebisch, incluida la aprobación de Juan Domingo Perón para que las Naciones Unidas lo contactara. También, en el Archivo Prebisch, Correspondencia: Eugenio Castillo a Raúl Prebisch, 19 de noviembre de 1948 y 5 de febrero de 1949; Raúl Prebisch a Eugenio Castillo, 10 de enero de 1949; y Martínez Cabañas a Raúl Prebisch, 3 de febrero de 1949.
} 
no podían permitirse un fracaso en La Habana. El Estudio Económico prometido para esa conferencia tenía que ser presentable y contrataron a Francisco Croire -otro ex empleado del Banco Central de la República Argentina que Raúl había enviado a una formación de posgrado - para dirigir la unidad latinoamericana de la Sección de Estabilidad y Desarrollo y apuntalar en Nueva York el Estudio Económico. Al llegar en diciembre de 1948, éste observó que se había hecho poca cosa durante los seis meses precedentes y que los dos funcionarios que había heredado eran de dudosa calidad y poco esfuerzo. Croire comentó desdeñoso que la moral y la competencia de los funcionarios de las Naciones Unidas en Nueva York contrastaba malamente con el viejo Banco Central de Buenos Aires. ${ }^{24}$

Croire volcó sus preocupaciones en una serie de largas cartas personales. ${ }^{25}$ Descubrió que el Estudio Económico había adquirido un valor simbólico considerable para el sistema de las Naciones Unidas en su conjunto, o al menos para América Latina en el seno de las Naciones Unidas. Había, señalaba, una creciente shadenfreude entre los escépticos de Nueva York, quienes dudaban que los economistas latinoamericanos tuvieran la competencia suficiente para cumplir a menos que fueran supervisados por superiores estadounidenses y europeos. Dado que el Estudio Económico era la obra más importante del Consejo Económico y Social (ECOSOC) relativa a América Latina, éste había pasado a ser, por tanto, una prueba de los propios economistas latinoamericanos. El Estudio Económico era único en el sentido de que los propios latinoamericanos eran responsables de él; constituía el primer informe internacional importante sobre la región dirigido y escrito por latinoamericanos y no por consultores extranjeros - en el FMI o el Banco Mundial los latinoamericanos eran miembros de equipos encabezados por economistas norteamericanos o europeos de alto nivel. Croire y otros latinoamericanos como él en Nueva York se sentían por lo tanto a prueba; el fracaso en La Habana confirmaría la percepción de Nueva York de que eran segundones. Esta situación duplicaba la importancia del papel de Prebisch. Nueva York movilizaría todos los recursos disponibles para reunir los distintos componentes destinados a elaborar un do-

\footnotetext{
24 Archivo Prebisch, Correspondencia: Francisco Croire a Raúl Prebisch, 24 de diciembre de 1948.

25 Archivo Prebisch, Correspondencia: Francisco Croire a Raúl Prebisch, 28 de febrero y 8 de abril de 1949.
}

cumento aceptable, incluso el envío de funcionarios de la Sede a Santiago en misiones de corto plazo. Se estaba recopilando una gran cantidad de datos; Santiago aceptaba ahora un plan de trabajo y un bosquejo del Estudio Económico más realista. Otros organismos como la FAO y el FMI colaboraban, y el Banco Mundial acababa de completar el estudio The Pattern of Latin American Trade with ERP Europe and the US, que era útil para el propio informe de la CEPAL titulado "Perspectivas de incremento del comercio", que se preparaba para La Habana. Dorfman y Alfonso Santa Cruz le dedicaban tiempo extra; Louis Shapiro de la Sede de Nueva York llegó a Santiago el 17 de diciembre a trabajar con Regino Boti sobre estadísticas regionales de comercio exterior. No obstante, el problema era el del liderazgo general: aunque el Estudio Económico tenía que ser producto de un trabajo en equipo, en último término una persona tenía que redactar un documento marco que estableciera un enfoque teórico y sus fundamentos. Croire se sintió aliviado cuando Prebisch aceptó este cometido; si no hubiera aceptado redactar el informe, las Naciones Unidas habrían recurrido a gente de fuera de América Latina, tal vez a la Suecia de Gunnar Myrdal, demostrando con ello al mundo el fracaso de los economistas latinoamericanos y augurando la segura desaparición de la CEPAL. ${ }^{26}$

Es más, La Habana estaba surgiendo de improviso como una reunión importante en las relaciones entre los Estados Unidos y América Latina. En parte, esto reflejaba el viejo tema de las expectativas frustradas de reconocimiento y cooperación estadounidense en la posguerra. En 1949 y a comienzos del segundo gobierno de Truman se estaba generando nuevamente una sensación de injusticia porque las prioridades de Washington se centraban en Europa y Asia. Durante la Segunda Guerra Mundial, los países latinoamericanos habían vendido sus productos básicos a los Estados Unidos a precios fijados por la Office of Price Administration (OPA), pero no habían podido convertir durante ese período sus ingresos en dólares en bienes con la inflación consiguiente. Ahora veían que cuando los bienes estadounidenses estaban finalmente disponibles para ser adquiridos, no había controles de precios sobre esas exportaciones industriales, aunque los precios de los productos primarios y agrícolas de

\footnotetext{
26 Archivo Prebisch, Correspondencia: Francisco Croire a Raúl Prebisch, 24 de diciembre de 1948. Asimismo, Naciones Unidas, Memorandum de W.R. Malinowski a Harold Caustin, Nueva York, 12 de noviembre de 1948.
} 
América Latina habían declinado. ${ }^{27}$ Al término de la guerra, los países monoproductores como Venezuela, Cuba, Chile y Bolivia encaraban una depresión inevitable del comercio, y estaban al borde de una grave crisis económica. Sin embargo, el gobierno de Truman no había implementado la mayoría de sus promesas de asociación económica formuladas durante la guerra. Washington se oponía ahora a la creación de un banco interamericano de desarrollo; continuaba postergando la tan anunciada conferencia económica interamericana; y rechazaba los esfuerzos multilaterales para estabilizar los precios de los productos básicos. Y lo peor de todo era que la oposición del Congreso de los Estados Unidos a ratificar la nueva organización internacional de comercio (OIC), que se había reunido en 1948, también en La Habana, tensionaba aún más las relaciones entre los Estados Unidos y América Latina. Concebida durante la Segunda Guerra Mundial, Keynes había considerado la oIC como la contraparte del FMI y el Banco Mundial; su descalabro dejó desilusionados y frustrados a los latinoamericanos. La secuencia de la gran depresión, la guerra y el desafío del ajuste en la posguerra a la Pax Americana había creado un regionalismo incipiente en América Latina - una conciencia de experiencias compartidas, e incluso de mayores necesidades-, albergado por una nueva generación de profesionales más capacitados y viajados. Los jóvenes latinoamericanos ansiaban simultáneamente el reconocimiento, el liderazgo y la definición; había una oportunidad para las nuevas ideas y el cambio. ¿Existe América Latina? había preguntado el autor mexicano Luis Alberto Sánchez algunos años antes, en la década de 1940. América Latina era una región pronta a ser creada, y esta idea y oportunidad se sirvieron de los agravios percibidos para otorgar a la conferencia de la CEPAL en La Habana en 1949 una significación simbólica fuera de toda proporción con la agenda real de la reunión. ${ }^{28}$

La carga adicional de la inquietud y expectativas evidentes de la CEPAL, las Naciones Unidas y América Latina aumentaba la angustia de Raúl al iniciar sus labores en una oficina situada en la planta superior al extremo del corredor, algo apartada del resto del personal de la CEPAL, haciendo una pausa sólo para su almuerzo diario con Adelita en Providencia. Necesitaba

${ }^{27}$ Estados Unidos, Departamento de Estado, "Latin American Policy Statement", Memorandum de E. Miller a Louis J. Halle, 14 de noviembre de 1950.

28 Archivo Prebisch, Correspondencia: Francisco Croire a Raúl Prebisch, 24 de febrero de 1949. obtener un avance decisivo, pero se sentía alicaído, tan alicaído como en sus últimas conferencias en la facultad en 1948 y una serie de seminarios que había completado recientemente en México. Ahora comprendía plenamente el costo de sus años de marginación. Cuando dejó el Banco Central en 1943 y redactó el bosquejo de "La moneda y el ritmo de la actividad económica", se hallaba bien a la delantera del resto en su desarrollo teórico. Su concepto central de una brecha estructural en la economía internacional entre los países industriales y agrícolas en que las fuerzas del mercado tendían a acentuar las desigualdades había sido novedoso y apasionante. Pero eso había sido más de cinco años antes. Parecía al borde de una innovación muy importante; tantas cosas habían parecido posibles, pero no había logrado concretarlas. Había progresado por cierto; desde 1945 había injertado en su análisis la terminología centro-periferia, empleada por primera vez en 1921, para acentuar el dualismo presente en la economía internacional, y ésta era una parte integrante permanente de sus escritos. El trabajo sobre el ciclo económico también había avanzado notoriamente. Pero la disciplina no consistía tampoco en quedarse quieto, y los economistas más jóvenes ya entraban a ocuparse de la economía del desarrollo; el argumento, por ejemplo, de que los exportadores agrícolas se hallaban en desventaja comparados con los exportadores industrializados en el comercio internacional estaba pasando a ser un lugar común (Love, 1994). Si bien ningún otro académico había dado todavía una respuesta a la hipótesis planteada por Prebisch en "La moneda y el ritmo de la actividad económica” de 1943, era sólo cuestión de tiempo para que perdiera esta carrera y también aquélla con los académicos de Europa y América del Norte.

Raúl se sentía cercano a una nueva síntesis, pero transcurrían los días en Santiago y aumentaba su frustración a medida que se aproximaba el plazo para La Habana. A principios de abril distribuyó un texto preliminar a los colegas de la CEPAL para que formularan sus observaciones. Furtado leyó el manuscrito y quedó decepcionado. El estilo era académico y a la defensiva, y se ocupaba de temas familiares, la declinación del coeficiente de importaciones estadounidenses, los controles de capital, el comercio exterior, el ahorro y la inflación, y la importancia de la industrialización. ${ }^{29}$ El documento parecía más bien un compendio de sus

\footnotetext{
29 Tanto Furtado (1985) como Toye y Toye (por publicarse) son fuentes importantes sobre este episodio. La extensa entrevista del autor con Celso Furtado en 1990 proporcionó nuevas luces para redactar el presente artículo.
} 
conferencias en la facultad y en México que un documento de política, y aunque estaba animado por su terminología "centro-periferia", su explicación de este capitalismo asimétrico era incompleta, y a diferencia de "La moneda y el ritmo de la actividad económica" de 1943, al parecer no se refería a la declinación de la relación de precios del intercambio. Prebisch se esforzaba claramente a medida que el plazo se aproximaba, consciente de que su trabajo no estaba a la altura de lo que sabía que podía lograr. ${ }^{30}$

Lo que ocurrió a continuación ha sido relatado magistralmente por Furtado en su autobiografía (Furtado, 1985, p. 60). Mientras Prebisch se debatía en Santiago, Croire recibía en Nueva York un ejemplar del proyecto de informe que el Dr. Hans Singer había escrito para la Subcomisión de Desarrollo Económico de las Naciones Unidas titulado Post-war Price Relations Between Under-developed and Industrialized Countries. ${ }^{31}$ Lo increíble es que ya el 17 de diciembre Castillo también había recibido un ejemplar anticipado del documento de Singer —en esa fecha el estadístico de las Naciones Unidas Louis Shapiro llegó de Nueva York para trabajar en el Estudio Económico-, pero no lo había compartido con Prebisch. ${ }^{32}$ Croire advirtió la renuencia de los altos funcionarios a que se distribuyera, ya que el informe de Singer cuestionaba la opinión ortodoxa y por lo tanto probablemente sería rechazado por la Subcomisión de las Naciones Unidas, pero se lo envió de inmediato a Raúl a México junto con otro documento del FMI sobre comercio exterior.

Prebisch no se había encontrado jamás con Singer, un académico de origen alemán que dejó su país en 1933 y obtuvo un doctorado en la Universidad de Cambridge. Contratado por David Owen para trabajar en el Departamento de Asuntos Económicos y Sociales de las Naciones Unidas, había llegado a Nueva York en abril de 1947 con una licencia por dos años otorgada por la Universidad de Glasgow. Aquí inició sus labores en la sección comercial de ese Departamen-

\footnotetext{
${ }^{30}$ El propio Prebisch jamás se refirió en sus entrevistas posteriores a esta transición hacia el "manifiesto" en Santiago. Furtado (1985), Toye y Toye (por publicarse) y el propio trabajo del autor subrayan que a comienzos de 1949 se produjo un punto de inflexión importante en la labor de don Raúl.

${ }^{31}$ Retitulado después como Relative Prices of Exports and Imports of Under-Developed Countries (Naciones Unidas, 1949).

32 Archivo Prebisch, Correspondencia: Gustavo Martínez Cabañas a Raúl Prebisch, 5 de marzo de 1949, y Francisco Croire a Raúl Prebisch, 8 de abril de 1949. El tema es analizado también in extenso en Toye y Toye (por publicarse).
}

to con un grupo interesante de economistas que pronto señalaron a su atención el problema de la relación de precios del intercambio (Singer, 1984, pp. 275-311). Singer sostenía que las estadísticas históricas demostraban una declinación de la relación de intercambio de los países en desarrollo. Desde la última parte del siglo XIX hasta la víspera de la Segunda Guerra Mundial, un período de más de medio siglo, había una tendencia secular descendente de los precios de los bienes primarios en relación con los precios de los bienes manufacturados ( Toye y Toye, por publicarse, p. 25). Tal declinación brindaba un incentivo adicional para la industrialización en los países en desarrollo, puesto que de otro modo perderían recursos para el desarrollo en relación con sus contrapartes industrializadas (Naciones Unidas, 1949, pp. 16-17).

Pero el artículo de Singer era el estímulo que necesitaba Prebisch para escapar de su creciente frustración y temor al fracaso. En su bosquejo de "La moneda y el ritmo de la actividad económica”, de 1943, Raúl ya había asumido la declinación secular de la relación de intercambio internacional para los países agrícolas, y tanto Kindleberger como Samuelson habían escrito artículos basados en esta hipótesis. ${ }^{33}$ Pero Singer no sólo lo demostraba estadísticamente dentro de un estudio histórico riguroso, sino que también articulaba las implicaciones éticas de la declinación de la relación de intercambio en la economía mundial que creaba una brecha entre países ricos y países pobres. Por lo tanto, Prebisch reconocía un alma gemela en el economista británico; el estudio de Singer no sólo corroboraba sus supuestos sobre el comercio, sino que le otorgaba también la confianza para reescribir su trabajo con una nueva estructura y estilo. ${ }^{34}$ Raúl recobró la energía y reanudó su tarea, asegurándose de que todos los ejemplares de su trabajo anterior se recogieran y desecharan. Luego en tres días con sus noches escribió El desarrollo económico de la América Latina y algunos de sus principales problemas (Prebisch, 1949), en que desapareció la prosa forzada de su trabajo previo, reemplazado por un ensayo que recorda-

\footnotetext{
33 Kindleberger (1943) y Samuelson (1948). El Archivo Prebisch (en particular la correspondencia de Prebisch con Víctor Urquidi, como la del 2 de junio de 1944, que trata en detalle el trabajo de Kindleberger) da luces importantes acerca de la evolución de las reflexiones de Prebisch sobre las teorías económicas emergentes durante el período 1943-1949.

${ }^{34}$ El respeto de toda una vida de Prebisch por Hans Singer no flaqueó jamás durante la larga amistad personal que siguió a la visita de Singer a Santiago en 1950. El sentimiento era absolutamente recíproco.
} 
ba el dominio y la simplicidad de Keynes. Puede que el nuevo documento no haya sido académico conforme a la definición de las revistas oficiales; ni tampoco estaba repleto de fórmulas matemáticas, hipótesis explícitas o llamadas de pie de página. Ninguno de los distintos componentes o su argumento eran completamente novedosos —es correcto, por ejemplo, identificar el hito de la relación de intercambio como la "teoría Prebisch-Singer"-, pero el genio del "manifiesto" de Raúl consistió en moldear estos componentes dispares en una síntesis única y convincente. Logró reexaminar los determinantes de la actividad económica en los países en desarrollo, y representó un hecho clave que cambió el vocabulario del desarrollo internacional y marcó un nuevo período en América Latina.

El "manifiesto" de 1949 comenzaba con un llamado a la razón, lo que me mueve a parafrasear la máxima de Aristóteles de que los hechos no han sido todavía suficientemente establecidos. Si alguna vez lo son, el mérito debe atribuirse a la observación y no a las teorías, y a las teorías sólo en la medida que sean confirmadas por los hechos observados. Los latinoamericanos debían tener el valor de confrontar su propia realidad para hallar soluciones, y esto significaba someter la sabiduría heredada a los interrogantes fundamentales: ¿Esto funciona? ¿Quién gana y quién pierde? Conocer significa ser libre y capaz de controlar el propio destino, señalaba el "manifiesto", y Prebisch articuló un marco inolvidable, aunque engañosamente simple, para explicar por qué el sistema no estaba obrando en el interés mutuo de las naciones ricas y pobres, por qué los países industriales cosechaban las mayores ganancias, y qué había que hacer para restablecer la igualdad para América Latina en la economía internacional. El desarrollo económico de la América Latina y algunos de sus principales problemas de 1949 le debía mucho al bosquejo de Prebisch "La moneda y el ritmo de la actividad económica", de 1943. Se observa el mismo tono confiado, el mismo distanciamiento de los datos para destacar los puntos claves, y la misma convicción de que el dilema que confrontan los países de la región podía superarse con éxito.

Pero el "manifiesto" era diferente en cuanto a su visión regional y llamado a la acción. El concepto "centro-periferia" de la economía mundial estaba centrado de manera mucho más explícita en la dinámica y estructura de la desigualdad mundial. Comenzaba con la demanda de una economía mundial unificada en que todos los Estados, industriales y en desarrollo, estuvieran vinculados en un sistema único de intercambio y afectados por un ciclo económico común. Sin embar- go, dentro de este sistema contraponía los papeles tan distintos de los países industriales ricos frente a los países agrícolas en desarrollo: estos últimos producían productos primarios para los primeros a cambio de bienes manufacturados, mientras que el ciclo económico se iniciaba en los países centrales y se difundía a la periferia. Prebisch sostenía luego que la distribución de los beneficios era desigual porque la dinámica del comercio exterior y el ciclo económico favorecían a los países industriales. Esto no era mala voluntad de los gobiernos, sino más bien el funcionamiento inherente del sistema: que los aumentos de productividad eran mayores en los bienes industriales, que en los primarios podía documentarse por la declinación de la relación de intercambio que él había supuesto en 1943 y que ahora Singer había documentado. A su vez, este factor era agravado por el ciclo del comercio internacional en que los países agrícolas eran más vulnerables que las economías centrales durante las recesiones, porque el trabajo organizado en Europa o América del Norte tenía la fortaleza suficiente para impedir un colapso de precios equivalente. El resultado de ambos factores - la declinación secular de la relación de intercambio y la vulnerabilidad del ciclo económico- explicaba el error fundamental de la teoría neoclásica del comercio que suponía iguales beneficios para los exportadores industriales y agrícolas y a la que se le suponía igual validez en América Latina que en los Estados Unidos o Gran Bretaña. Había, en suma, una asimetría inherente en el sistema, cuyo conocimiento era un paso necesario para comprender la inserción de América Latina en la economía internacional e idear con ello un nuevo enfoque apropiado para sus necesidades futuras. ${ }^{35}$

La atracción del "manifiesto" radicaba en su objetivo dual; no sólo ofrecía un diagnóstico convincente, sino que además contenía una visión que prometía a los países agrícolas una salida a su dilema. Ser periférico no era necesariamente ser dependiente; tal como en "La moneda y el ritmo de la actividad económica" proponía que la industrialización, con el debido cuidado para evitar la inflación y las distorsiones, ofrecía a América Latina la perspectiva de revertir la dinámica del intercambio desigual que de otra manera la condenaba a beneficios constantemente decrecientes en la economía

\footnotetext{
35 Dentro de la vasta literatura sobre este tema, nótense los estudios recientes de Love (1996); Rodríguez (1998); Gurrieri (1983); Mallorquín (1994) o Sprout (1992). Son valiosos también todos los artículos incluidos en Iglesias, ed. (1994). Véanse asimismo Spraos (1980) y Tanzi y Chu (1989).
} 
mundial. Aquí había una prescripción para el cambio no revolucionaria, no comunista, que todos los gobiernos de la región, independientemente de su orientación ideológica, podían aplaudir. Era un llamado a la acción que Prebisch basaba directamente en su experiencia en Argentina, donde la sustitución de importaciones ya había avanzado considerablemente antes de 1914, y donde el Banco Central había cumplido precisamente esta función hasta el punto de que en 1943 la producción industrial igualaba la de la agricultura en la economía nacional. Desde una perspectiva regional en que la mayoría de las economías eran menos desarrolladas que Argentina, era una innovación realmente atrevida. Pero una vez divulgada, su desafío a las economías periféricas de pasar de la producción de productos básicos a una economía más diversificada se demostró duradero e irresistible — tanto así que hoy se da por descontado que la originalidad del "manifiesto" ha quedado oscurecida por su éxito.

El "manifiesto" contenía otros elementos latentes en su prosa extraordinariamente elegante y fluida. A pesar de su llamado a la razón y el argumento mesurado, hay un trasfondo de indignación casi imperceptible pero inconfundible en el texto. La economía del desarrollo, sugería Prebisch, significaba asumir una postura. El trato que acababa de recibir en Washington explicaría en parte este tono, así como el pesimismo comercial de 1949, cuando las perspectivas de incrementar las exportaciones latinoamericanas eran sombrías. Los Estados Unidos habían caído en recesión, el proveedor dominante de la región desde la Segunda Guerra Mundial, con un aumento de $168 \%$ de las importaciones latinoamericanas, mientras las de Europa occidental caían en 15\%. "En otros tiempos, antes de la gran depresión, los países de América Latina crecieron impulsados desde afuera por el crecimiento persistente de las exportaciones. Nada autoriza a suponer, al menos por ahora, que este fenómeno haya de repetirse con análoga intensidad, salvo en casos muy particulares". ${ }^{36}$ Dada esta perspectiva desalentadora, era aun menos probable que el sistema eco-

\footnotetext{
36 Prebisch, 1949, pp. 11 y 48-50. Las perspectivas de las exportaciones latinoamericanas eran sombrías en los Estados Unidos y Europa y también en América Latina. Además, la recesión en los Estados Unidos coincidía con una transformación de las relaciones comerciales Estados Unidos-América Latina-Europa entre 19371949, período en que las exportaciones europeas a la región habían sufrido una caída de $15 \%$ comparada con un incremento de $168 \%$ de las estadounidenses, mientras que las exportaciones latinoamericanas a Europa caían en $39 \%$ y las destinadas a Estados Unidos subían en $38 \%$.
}

nómico internacional estimulara el desarrollo y el progreso técnico en América Latina, y por tanto era urgente proceder sin demora. ${ }^{37}$

El informe de Prebisch transformó la reunión de La Habana y causó sensación en los medios de comunicación de masas en toda América Latina; en vez de debatir un Estudio Económico importante pero aburrido, la CEPAL se encontró dueña de una gran idea y una causa potencial. Nadie podía dudar siquiera de que Prebisch había sido el eje del triunfo de La Habana, el gran vencedor. Todos, y él mismo, se daban cuenta de que La Habana lo había lanzado como una personalidad regional, y el 14 de junio, en la clausura de la conferencia, se aprobó por unanimidad una resolución formal de agradecimiento. Pero en Nueva York y Washington la reacción fue diferente; hubo consternación entre los altos funcionarios de las Naciones Unidas y los Estados Unidos, quienes comprendían el poder del "manifiesto": el marco del estructuralismo de Prebisch ofrecía un nuevo enfoque del desarrollo internacional; se había pronunciado por un Estado activo y la industrialización en un nuevo lenguaje que impugnaba la vieja doctrina de la ventaja comparativa. Fue socavada la noción de que los países agrícolas de América Latina podían prosperar en el futuro si permanecían como productores de productos básicos, y todos los expertos en desarrollo — tanto de los países industriales como de aquéllos en desarrollo- sabían que se había lanzado un nuevo debate. La reacción inmediata y dura de los economistas tradicionales como Gottfried Haberler, Gerald Baldwin, Charles Kindleberger y Gerald Meyer a El desarrollo económico de la América Latina y algunos de sus principales problemas subrayaba la gravedad del reto de Prebisch a la teoría económica tradicional. ${ }^{38}$ Jacob Viner, de la Universidad de Princeton, marcó la pauta al desechar el "manifiesto" como un conjunto de fantasías malignas, una conjetura histórica distorsionada e hipótesis simplistas. Durante las conferencias que dictó en Brasil en la Universidad Nacional en julio y agosto de 1950, la arrogancia de Viner asombró al auditorio tanto como sus consejos: quédense con el libre comercio; no abandonen las verdades neoclásicas atraídos por las sirenas que promueven la diversificación económica; dedíquense a la agricultura y al con-

\footnotetext{
${ }^{37}$ Furtado (1985, pp. 60-61) destacaba este punto, señalando que Prebisch había pasado de una crítica de la teoría económica a las "realidades" internacionales.

38 Véase en Solís (1989) un examen preliminar de las controversias académicas en torno a la tesis de Prebisch.
} 
trol de la natalidad. ${ }^{39}$ Prebisch era un hereje -incluso "un gran hereje" - que había que evitar a toda costa. Otros economistas estadounidenses eran menos ideológicos, con críticas que cuestionaban desde los datos empíricos que apoyaban los postulados de la teoría comercial de Prebisch-Singer hasta la omisión de los costos de transporte, el impacto de la innovación tecnológica, etc. ${ }^{40}$

Pero los críticos de Prebisch no entendían nada. El "manifiesto" no era una teoría del desarrollo económico plenamente elaborada, y Raúl no sostenía que lo fuera. De hecho, en el informe se pedía reiteradamente más investigación. No era anticomercio (mientras más activo sea el comercio exterior de América Latina, mayores serán las posibilidades de incrementar la productividad mediante la formación intensiva de capital). No era antiagricultura (la industrialización de América Latina no es incompatible con el desarrollo eficiente de la producción primaria). Tampoco era pro industrialización a ciegas. (El capítulo VI del informe se titula "Los límites de la industrialización", y señala que la industrialización no es un fin en sí, pero es el único medio de que disponen los países para obtener una participación en los beneficios del progreso técnico y elevar progresivamente el nivel de vida de las masas). ${ }^{41}$ Prebisch creía también en el mercado, pero exigía respuestas a la pregunta de ¿Qué más? ¿Qué pasa con las inequidades y la asimetría del sistema? Cuestionaba que el mercado fuera en sí el gran igualador, e instaba a una acción decidida para compartir los beneficios del comercio internacional. Este era el salto cognitivo que lo identificaba como el padre del desarrollo: había presentado un nuevo paradigma del desarrollo con un enfoque fundamentalmente novedoso. De hecho, la crítica más seria -y resentida- de Raúl a los economistas neoclásicos de las universidades estadounidenses y europeas era su presunción de sapiencia: una de las deficiencias conspicuas de la teoría económica general, desde el punto de vista de la periferia, sostenía, es su falso sentido de universalidad. Viner (que una vez reconoció que era un librecambista anticuado) y sus colegas no tenían dificultades para atacar el "manifiesto" en aspectos

\footnotetext{
${ }^{39}$ Prebisch fue invitado a Brasil para una visita prolongada, del 19 de agosto al 1 de septiembre de 1951, gran parte de la cual estuvo destinada a responder las críticas que había recibido de Viner el año anterior, las que habían sido publicadas en la Revista Brasileira de Economía en la Fundación Getulio Vargas.

${ }^{40}$ El Gran Heresiarca: la expresión que Furtado acuñó para Prebisch

y la CEPAL en el apogeo de su fama.

${ }^{41}$ Prebisch, 1949, p. 59 y siguientes.
}

concretos porque no era una teoría plenamente desarrollada, y por lo tanto era vulnerable a la crítica académica. Pero en el aspecto central de la asimetría, sólo podían recurrir a las viejas verdades — como la equidad del sistema si los países en desarrollo creaban un ambiente económico acogedor para la inversión.

\section{Conclusión: el Prebisch esencial}

Cabe sostener que Prebisch cambió menos que Washington y Argentina: entre 1943 y 1949 la guerra fría revirtió las políticas en Washington y el peronismo transformó Argentina. Las múltiples críticas a Prebisch - de que era un proteccionista ciego, o que era antiestadounidense- obscurecen la trayectoria de su verdadera vida y obra antes de $1943 .{ }^{42}$ El colmo de la ironía es que suele achacársele haber deformado el desarrollo latinoamericano para propiciar una sustitución de importaciones exagerada. De hecho, el imperativo ético que impulsó toda su vida emanaba de sus años de infancia en Tucumán, donde un puñado de magnates del azúcar mantenía un sistema de explotación de estilo colonial sobre los jornaleros migrantes indios, porque su poder en la capital nacional podía impedir la entrada de importaciones brasileñas más baratas. Como su padre, un inmigrante de Sajonia que contrajo matrimonio dentro de una rama más pobre de una de las familias coloniales más famosas de Argentina, tenía aversión por la oligarquía y los militares; era miembro fundador de la "generación dorada" de Argentina, y llegó a la capital comprometido con la reforma. Su decisión de estudiar economía, una disciplina nueva y carente de prestigio en esa época en Argentina que prometía pocas retribuciones, reflejaba el deseo de conocer los mercados para mejorar la sociedad dentro de la concepción original de la disciplina por Adam Smith. Este mismo idealismo lo indujo a elegir su carrera en la administración pública argentina cuando reconoció la modernización del Estado como su senda futura, y pasó pronto a convertirse en un tecnócrata destacado en 1928. El modelo de un banco central autónomo que ideó en 1935 fue el logro cimero de sus años argentinos, que captó su visión de una élite

\footnotetext{
42 Véase en Prebisch, 1949, pp. 20-21, su ataque contra la "falsa universalidad" de la teoría económica general. La noción más difundida, que se tornó prevalente en Washington durante los años cincuenta, de que Prebisch era antiestadounidense, queda totalmente desmentida por su vida y obra. Este aspecto se examina con todo detalle en la biografía por publicarse de Don Raúl escrita por el autor de este artículo.
} 
modernizante en Argentina para supervisar un proceso de desarrollo coherente protegido de la incertidumbre política - de igual manera formó la CEPAL (y más tarde la UNCTAD) como instrumentos para defender la equidad en las relaciones Norte-Sur. Resulta paradójico que, tras 54 años, el Informe sobre el Desarrollo Mundial 1977 del Banco Mundial aceptara la visión de Raúl de un Estado fuerte pero sagaz para corregir las externalidades del mercado, salvaguardar los bienes públicos y buscar ventajas competitivas en vez de ventajas comparativas en el comercio.

En 1943, cinco años antes del "manifiesto", Prebisch esbozó sus pensamientos sobre el desafío que encaraba Argentina; su visión nos parece familiar en el discurso actual sobre cómo hacer frente a la globalización —en particular la necesidad de aprovechar el mercado en el interés social mediante el establecimiento de un compromiso entre los beneficios de la liberalización, por una parte, y las opciones políticas necesarias para proteger los valores nacionales y los bienes públicos, por otra. Reiteramos que ahora conside- raríamos el enfoque de Prebisch como una "globalización civilizadora" para asegurar el crecimiento sostenible y el desarrollo social. Algunos supuestos del "manifiesto" (como el pesimismo exportador) resultaron ser incorrectos, pero su aporte perdurable no estriba en detalles ligados al tiempo. Más bien, su grandeza estriba en proyectar un paradigma que restituye el factor de poder a la economía internacional y exige que la teoría esté vinculada con la experiencia para interpretar la peculiar inserción regional de América Latina en la economía internacional. Esta vocación reflejó la interacción constante entre el práctico y el académico en su vida, la que hacia 1943 había demostrado con creces la falsa universalidad de la teoría económica neoclásica. La trayectoria breve y mediocre del Consenso de Washington sirve de recordatorio saludable del exceso ideológico y de la necesidad de nuevos enfoques que reflejen el contexto latinoamericano contemporáneo.

(Traducido del inglés)
Crossette, B. (1999): Ex-Premier of Singapore sees pitfalls in debt relief, New York Times, 14 de octubre.

Dosman, E. J. y D. H. Pollock (1993): Raúl Prebisch, 1901-1971: la búsqueda constante, en E. V. Iglesias (ed.), El legado de Raúl Prebisch, Washington D.C., Banco Interamericano de Desarrollo (BID).

(2001): Power and Economics: A Reflection on the Life and Work of Raúl Prebisch, Washington, D.C., BID.

Escudé, C. A. (1981): The Argentine eclypse: The international factor in Argentina's post World War II decline, Yale, Universidad de Yale, diciembre, tesis de doctorado.

Furtado, C. (1985): Fantasia organizada, Coleção Estudos Brasileiros, vol. 89, Rio de Janeiro, Paz e Terra.

Gurrieri, A. (1983): Technical progress and its fruits: The idea of development in the works of Raúl Prebisch, Journal of Economic Issues, vol. XVII, $\mathrm{N}^{\circ}$ 2, Sacramento, California, Association for Evolutionary Economics, junio.

Hosbawn, E. (1994): Age of Extremes: The Short Twentieth Century 1914-1991, Londres, Abacus.

Iglesias, E. V. (ed.) (1994): The Legacy of Raúl Prebisch, Washington, D.C., Banco Interamericano de Desarrollo (BID).

Kindleberger, C. (1943): Planning for foreign investment, American Economic Review, $\mathrm{N}^{\circ} 33$, Nashville, Tennessee, American Economic Association.

Lewis, P. H. (1990): The Crisis of Argentine Capitalism, Londres, University of North Carolina Press.

Lorenzutti, J. (1996): Historia del Banco Central de la Argentina, Buenos Aires, Universidad Abierta Interamericana.

Love, J. (1994): Economic ideas and ideologies in Latin America since 1930, The Cambridge History of Latin America, Cambridge, Massachusetts, Cambridge University Press.
(1996): Crafting the Third World: Theorizing Underdevelopment in Rumania and Brazil, Stanford, California, Stanford University Press.

Mallorquín, C. (1994): Un breve recuento de la deconstrucción del estructuralismo latinoamericano, Estudios latinoamericanos, año 1, $\mathrm{N}^{\circ}$ 2, México, D.F., Nueva Época.

Naciones Unidas (1949): Relative Prices of Exports and Imports of Under-Developed Countries, Lake Success, Nueva York, Departamento de Asuntos Económicos y Sociales.

Ocampo, J. A. (2001): Palabras del Secretario Ejecutivo de la CEPAL en la ceremonia de homenaje a Raúl Prebisch en conmemoración del centenario de su nacimiento, Santiago de Chile, Comisión Económica para América Latina y el Caribe (CEPAL), 17 de abril.

Prebisch, R. (1943): La moneda y el ritmo de la actividad económica, texto inédito, Archivo Prebisch, Santiago de Chile, diciembre.

(1949): El desarrollo económico de la América Latina y algunos de sus principales problemas, E/CN. 12/89, Santiago de Chile, CEPAL (copia de Archivo).

(1991a): Raúl Prebisch. Obras 1919-1948, Buenos Aires, Fundación Raúl Prebisch.

(1991b): Anotaciones sobre nuestro medio circulante. A propósito del último libro del doctor Norberto Piñero, Raúl Prebisch. Obras 1919-1948, vol. I Buenos Aires, Fundación Raúl Prebisch.

(1991c): De cómo discurre el profesor Olariaga, Raúl Prebisch. Obras 1919-1948, vol. I, Buenos Aires, Fundación Raúl Prebisch.

Rodrik, D. (1997): Globalization, social conflict and economic growth, Raúl Prebisch Lecture, Ginebra, Conferencia de las 
Naciones Unidas sobre comercio y Desarrollo (UNCTAD), 24 de octubre.

(2000): Markets, politics and globalization: Can the global economy be civilized?, G. Helleiner, Tenth Raúl Prebisch Lecture, Ginebra (UNCTAD), 11 de diciembre.

Rodríguez, O. (1998): Aprendizaje, acumulación, pleno empleo: las tres claves del desarrollo, Desarrollo económico, vol. 38, $\mathrm{N}^{\mathrm{o}}$ 151, Buenos Aires, Instituto de Desarrollo Económico y Social (IDES), octubre-diciembre.

Samuelson, P. (1948): International trade and equalization of factor prices, Economic Journal, $\mathrm{N}^{\circ} 58$, Oxford, Reino Unido, Basil Blackwell.

Singer, H. (1984): The terms of trade controversy and the evolution of soft financing: Early years in the UN, G. Meier y D. Seers (eds.), Pioneers in Development, Nueva York, Oxford University Press.
Solís, L. (1989): Raúl Prebisch en CEPAL: años de esfuerzo intelectual creativo, Ensayos ocasionales, $\mathrm{N}^{\mathrm{o}} 10$, Santiago de Chile, Corporación de Investigaciones para el Desarrollo (CINDE).

Spraos, J. (1980): The statistical debate on the net barter terms of trade between primary commodities and manufacturers, Economic Journal, vol. 90, № 357, Oxford, Reino Unido, Basil Blackwell.

Sprout, R. (1992): El pensamiento de Prebisch, Revista de la CEPAL, $\mathrm{N}^{\circ}$ 46, LC/G.1717-P, Santiago de Chile, CEPAL.

Tanzi, V. y Chu, K. (1989): Fiscal Policy for Stable and Equitable Growth in Latin America, IMF working paper, $\mathrm{N}^{\circ}$ 93, Washington, D.C., Fondo Monetario Internacional (FMI).

Toye, J. y R. Toye (por publicarse): The Origins of the PrebischSinger Thesis, Journal of Political Economy, Chicago, Illinois, the University of Chicago. 